\title{
Getting the British back on bicycles-The effects of urban traffic-free paths on everyday cycling
}

\author{
Tim Jones* \\ Faculty of Technology, Environment and Design, Oxford Brookes University, Gipsy Lane Campus, Oxford OX3 OBP, United Kingdom
}

\section{A R T I C L E I N F O}

Available online 11 February 2012

\section{Keywords:}

Cycling

National cycle network

Traffic-free paths

\begin{abstract}
A B S T R A C T
The UK National Cycle Network (NCN) developed by the transport organisation, Sustrans, is a significant policy intervention aimed at encouraging cycling. Around half of the population is purported to live within one mile of the $20,000 \mathrm{~km}$ Network. Traffic-free paths (separated from the public highway away from motor traffic) form about one third of the Network but account for around $80 \%$ of trips. The importance of NCN urban traffic-free paths in encouraging people to cycle is often assumed but despite large aggregate datasets characterising users, there is no research on the effects on the local communities which they serve. This paper presents research which aimed to identify the contribution of a typical section of NCN urban traffic-free path in encouraging cycling for everyday travel amongst a community living adjacent to this type of intervention.

First, the paper outlines the characteristics of the NCN, the philosophy behind the development of urban traffic-free paths and the barriers to cycling which such interventions seek to overcome. Then findings of a controlled cross-sectional survey of two neighbourhoods in a medium size town in the English Midlands (which are demographically similar except that one is located adjacent to a section of NCN urban traffic-free cycle path intervention) are discussed.

In conclusion the paper reveals that provision of NCN urban traffic-free cycle paths alone may be insufficient in encouraging a shift from car to cycling for everyday travel purposes. The data from the study corroborates evidence that suggests that a wider co-ordinated multi-faceted approach to promoting cycling is required which combines social marketing with physical measures including; wider speed restrictions in urban areas, investment in high quality segregated cycle facilities on major roads, and general land use and transport policies that 'advantage cycling' and reduce the convenience of the car.
\end{abstract}

(c) 2012 Elsevier Ltd. All rights reserved.

\section{Introduction}

Visions of future low carbon sustainable transport routinely feature cycling. Replacement of short journeys by car with cycling in urban areas could help to reduce traffic congestion, improve the quality of the urban environment, benefit personal health and wellbeing and contribute towards a low carbon economy. However, rates of cycling for everyday travel in the UK have continued to decline as lifestyles have become more car dependent and cycling marginalised. Half of all car journeys in the UK are still less than five miles and around one third are less than two miles (DfT, 2007a). Targeting short trips by car that could potentially be replaced by cycling does not require a large investment by government (at least relative to other big infrastructure solutions) to make them an option for most people (Mackett, 2003). Research on consumer

\footnotetext{
* Tel.: +44 1865483436 .

E-mail address: tjones@brookes.ac.uk
}

acceptance of sustainable transport by Defra (2008) has revealed that walking and cycling less than three miles is a more acceptable behavioural goal than that of purchasing more fuel efficient/low carbon cars and using public transport. This suggests that there is a large untapped potential to increase cycling (and walking) for short journeys in urban areas which could not only contribute to reducing traffic congestion, but also to reducing transport's contribution to global carbon emissions, improving the quality of the urban environment and improving the nation's health.

The UK National Cycle Network (NCN) is a significant policy intervention aimed at creating a cycling culture. The importance of urban traffic-free cycle paths in encouraging people to cycle is often assumed, but despite large aggregate datasets characterising users, there is no research on the effects of such interventions on the local communities which they serve. This paper reports on empirical research that used a controlled cross-sectional design to survey neighbourhoods in a medium size town in the English Midlands that are demographically similar but exhibit differing levels of access to NCN urban traffic-free cycle path interventions. 


\subsection{Background: the UK national cycle network}

Sustrans, the organisation responsible for the development of the National Cycle Network (NCN), aims to enable people, "to travel by foot, bike or public transport for more of the journeys we make everyday' (Sustrans, 2011; 'Our Way of Thinking'). The organisation first started to develop what would be the first sections of the Network towards the end of the 1970s by creating a five mile traffic-free cycle path along the disused railway track between Bath and Bitton near Bristol in the south west region of England (Figs. 1 and 2). By 1994 Sustrans had developed short sections of cycle route across the UK and started to promote the concept of a National Cycle Network. In 1995 it was awarded $£ 43.5$ Millennium Lottery Grant towards the estimated $£ 200 \mathrm{M}$ to develop this Network in its entirety. This sizeable allocation was significant in that it was second only to that awarded for the development of the high profile Millennium Dome in London.

In 2000 Sustrans successfully completed 5000 miles of the National Cycle Network and by 2005 the 10,000th mile was opened providing an estimated 30 million people with access to within two miles of their home. Most of the Network comprises a series of linked traffic-free paths (typically along river corridors or disused railway lines) and low trafficked roads many of which linked urban centres with the green belt and outlying countryside. The NCN is a composite of over a thousand local sections and each one is designed to be of benefit to local people (Cope et al., 2003).

The National Cycle Network is regarded by Sustrans and its partners as a major 'symbolic new start' for cycling. Local authorities and other partners support the project on the premise that it will bring benefits in terms of traffic reduction, improvements to health, improved economic prospects, inclusive transport opportunities and a safer travelling environment. Successive governments have continued to provide a supporting role and this in turn gives Sustrans a strong mandate to go forward and encourage further stakeholder support:

We believe that by making it easier for people to walk and cycle safely for all types of local journey, the National Cycle Network is making a valuable contribution to the creation of a 'walking and cycling culture', where walking and cycling

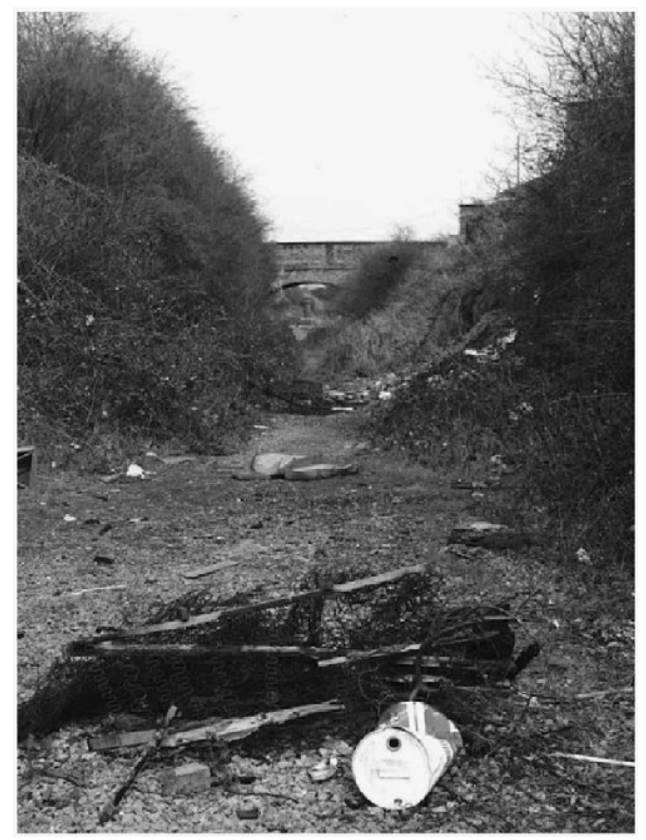

Fig. 1. Bristol and Bath Railway Path in the 70's, before becoming one of the most well used walking and cycling paths in the UK (credit: Sustrans).

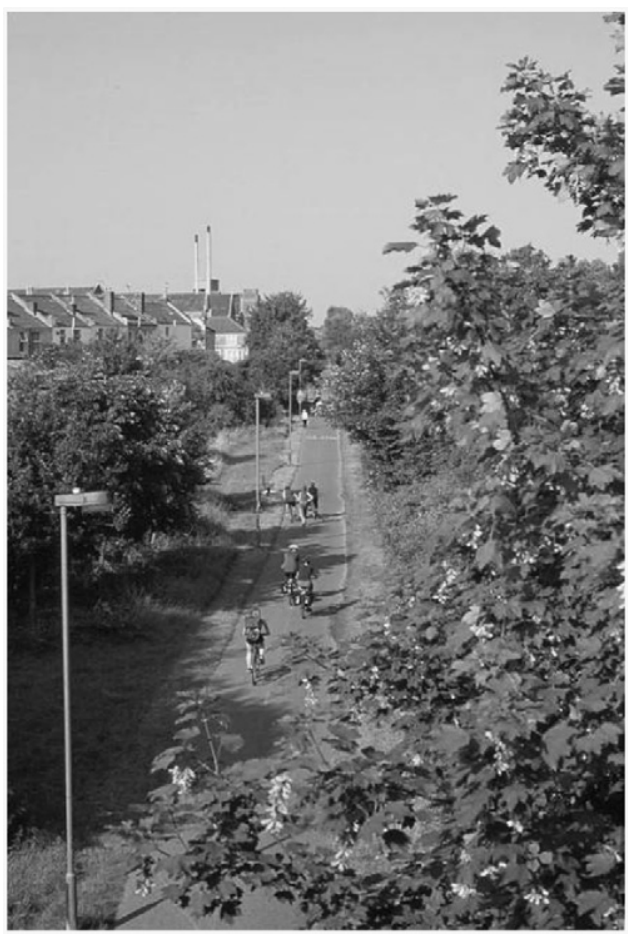

Fig. 2. Looking down on Bristol-Bath route at Easton, 2003 (credit: J. Bewley, Sustrans).

progressively become part of people's day-to-day lives. For that reason we are keen to support the continuing development of the Network, especially where this can provide improved access to schools, jobs, services and leisure. (DfT, 2004; p. 28)

\subsubsection{The intended role of traffic-free paths}

One of the principal aims of the NCN is to encourage people to take up cycling for the first time or to start cycling again. One assumption is that NCN traffic-free routes provide the opportunity for less experienced cyclists to gain the confidence and experience necessary to enable them to cycle more.

The novice cyclist stands to benefit the most by gaining confidence on the Network, its traffic-free, speed-calmed or lightly trafficked routes [provide] the perfect nursery slopes for acquiring the skills in relative safety. (Wickers, 2000; p. 44)

Sustrans' philosophy is that by creating at least one high quality traffic-free cycle route in every urban area people could be persuaded to cycle again, enjoy the experience, and convince themselves that the bicycle was still a valuable and appropriate means of transport for everyday use (Fig. 3).

Sustrans' annual Route User Monitoring Reports (RUMRs) provide evidence that there has been year-on-year growth of around $10 \%$ on the NCN (excluding new routes). Whilst actual route length has grown by $98 \%$ over the 5 years since 2000 usage rose by $135 \%$ (Fig. 4) over the same period (Sustrans, 2006). Sustrans states that traffic-free sections of the NCN in particular are crucial to the increased use of the Network. Traffic-free sections account for less than $20 \%$ of the Network but carry over $80 \%$ of all trips-approximately 193 million journeys in 2005 . Around $60 \%$ of all trips by bicycle that take place on the Network are made on urban traffic-free routes (ibid).

Since 1996 the on-going National Travel Survey (NTS) has reported that the average distance travelled by bicycle has fallen 


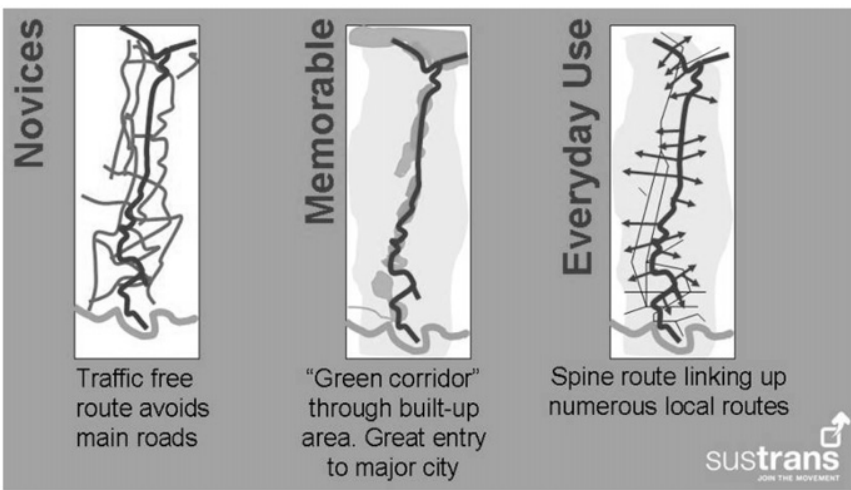

Fig. 3. Typical characteristics of traffic-free paths in urban areas. Source: Sustrans.

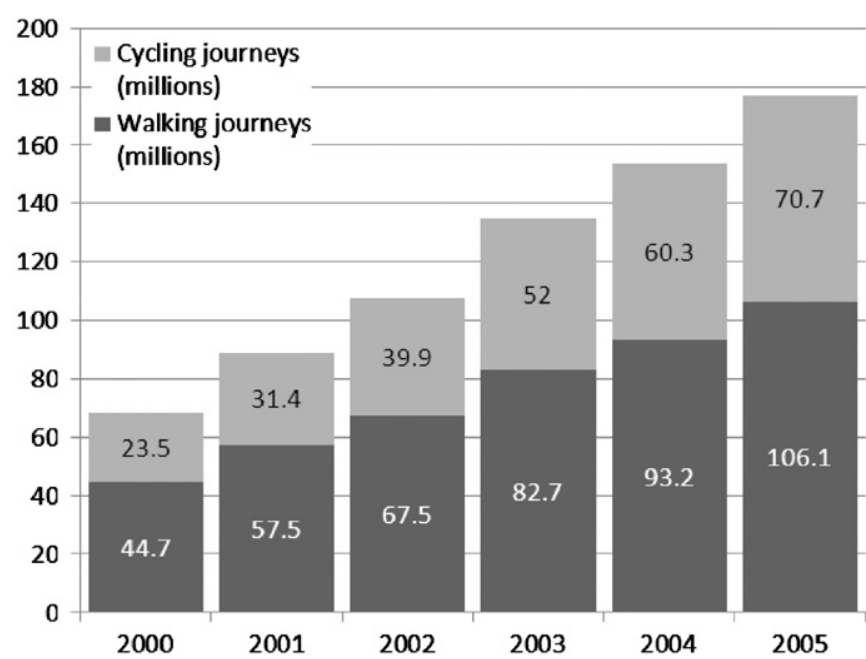

Fig. 4. Growth in walking and cycling on urban traffic-free sections of the National Cycle Network over the period 2000 to 2005.

Source: Sustrans.

by more than $10 \%$ overall and the number of cycling trips has also declined although this has stabilised (DfT, 2006). It is important to note however that the NTS does not record cycling (and walking) trips that take place off the public highway and therefore does not include Sustrans' own reported growth in cycling along trafficfree sections of the NCN. This suggests that the nature of cycling is undergoing a transformation away from mixing with traffic towards traffic-free routes. Indeed, Sustrans continues to argue that these trips need to be recorded in official government statistics (Sustrans, 2006) ${ }^{1}$ as this provides crucial evidence of the true picture of the demand for cycling in the UK.

\subsubsection{Alternative discourse on the effects of traffic-free path interventions}

I've always seen it as critical to have a positive strategy to start people cycling again-and you don't start with the journey to work. The way into cycling, that first journey, will almost certainly be a leisure journey.

(John Grimshaw, former Director of Sustrans, quoted in Sloman, (2006); p. 110)

${ }^{1}$ Sustrans continues to urge the government to include data from traffic-free routes of the National Cycle Network in order to achieve a much fairer assessment of the state of cycling in the UK.
Sustrans has, in the past, been criticised for focussing too much on traffic-free paths (that are mainly used for leisure journeys) and for adopting strategy that is doing little to lead more people to cycle competently and safely, wherever they wish to travel, and in a way that is sustainable and commands respect as an equal to others on the road. This criticism tends to be underlined by Forester's (2001) theory that 'bikeways' are the 'concrete expression of society's inferiority view of cycling' which proclaims motorists endanger cyclists and the way to protect cyclists is to build more bikeways (the so-called 'cyclist-inferiority phobia'). Pucher and Dijkstra (2000) acknowledge that this type of infrastructure is often more palatable and that motorists are less likely to object to off-road bike paths for recreational cycling because they do not interfere with the motor traffic on the roads. This may explain why local authorities and politicians have embraced the less controversial approach to traffic-free route path provision promoted by Sustrans. However, Pucher (2001) also recommends accommodating the vehicular cycling on the public highway that Forester espouses but not to the exclusion of separate facilities. The author is critical of a sole focus on the "vehicular cycling approach' which he regards as aimed at serving fast cycling and well-trained cyclists whilst ignoring the willingness, desire or need of people to cycle at lower speeds. The UK Department for Transport's position would appear to concur with this:

Although we want people to be able to cycle safely on the roads, we recognise that high quality traffic free routes have a role to play in encouraging people to cycle more. (DfT, 2007b; p. 18)

This raises an important issue as to whether more weight has been given to initiatives that encourage recreational cycling (either as a support system to aid the transition into functional cycling or indeed as a resource in its own right) at the expense of (arguably more difficult) efforts to develop the infrastructure and support for everyday functional cycling. As Parkin et al. (2007) state, 'it cannot be assumed that use of the bicycle for recreational purposes will follow through into use for utilitarian purposes'.

\subsubsection{The evidence gap}

Considerable effort, time and money has been spent developing the National Cycle Network in the hope that the project will capture the imagination of the population generating a cultural response to cycling whilst also acting as a stepping stone for new and returning cyclists. Councils have been busily allocating funds for cycling to develop (typically traffic-free) Sustrans routes within their authority boundaries. Critics of this approach would perhaps argue that this money would have been better spent elsewhere in promoting cycling, vehicular cycle training, improved conditions for cycling on the highway, and for measures that promote the treatment of cyclists as 'equals' to other road users.

Sustrans does not have substantive evidence that people using the NCN are converting to using cycles for everyday travel. Furthermore, Sustrans' own route usage monitoring surveys are not detailed enough to allow closer interrogation of this theory. Cope et al. (2003) state that, 'figures [from the route monitoring programme] conceal the role of the NCN as a demonstration project that provides a safe try-out space for potential cyclists, who may eventually develop from recreational cyclists to utility cyclists'. The authors identify the need for a strategic assessment of the ways in which the NCN can assist in key policy areas; the need for improved mechanisms for information dissemination in terms of reaching target audiences, promoting the availability of the resource, communicating route alignment and brand recognition. From their analysis of existing route user data the authors 
conclude that there is a need to include non-user populations in future samples and to establish a control exercise to discern the magnitude of impacts related to initiatives (pp. 16 and 17).

Lawlor et al. (2003; pp. 96-101) have also pointed out that strategies that seek to change the environment to one that is supportive of regular commuting by bicycle (or on foot) have an important part to play in increasing population activity levels. They argue that there is an urgent need to evaluate environmental interventions that are targeted at increasing levels of physical activity amongst the population such as the National Cycle Network-arguably the UK's largest such intervention. And whilst acknowledging that evaluation is not straightforward they propose, 'combining evidence from network user surveys, routine transport surveys, and linking details of development of the network with routine surveys to compare modes of transport and levels of activity between areas close to and more distant from a network path' (p100). Similarly, Bauman (2005) has called for the prioritisation of natural experiments and the opportunistic evaluation of environmental improvements in order to improve the evidence base as to their effects on cycling (and walking) activity.

The next section reports on the research approach and methods used to develop a better understanding of the links between physical environmental interventions, namely Sustrans trafficfree paths in urban areas, and the current (and the future) role of cycling in the lives of residents at neighbourhoods served by those facilities.

\section{Research approach and methods}

A cross sectional research design was applied to a particular case study location for this study in order to generate concrete, practical and context dependent knowledge (Flyjberg, 2001; p. 70) of the effects of a section of Sustrans traffic-free cycle route. It was considered vital that the nature of the case study (e.g. whether it is typical in some way or other on a series of attributes) and the boundaries of the study population were clearly identifiable and kept in focus (Stake, 2000). This would enable the research to act as an exemplar of cycling behaviour within a specific context (i.e. traffic-free route providing direct access between residential areas and everyday facilities) to enable findings to be generalised to theory (i.e. that this proximity encourages cycling for everyday travel).

In order to follow this logic, Stafford (Fig. 5) a medium sized town in the English Midlands (population 111,500) was identified as a suitable case study. The town has average levels of cycling (3\% journeys to work from Census 2001) and significant sections of traffic-free cycle route have been developed. The NCN through Staffordshire joins Stafford urban area via three mostly traffic-free routes that are highly visible on the ground and which all converge in the town centre (Fig. 6). Each route provides the local population with the opportunity for traffic-free recreational access to the countryside as well as serving utility journeys to access the commercial centre as well as business parks and industrial estates along the routes. ${ }^{2}$ In this context it can be assumed that there are realistic opportunities of replacing short car journeys with cycling.

One of the routes, The Isabel Trail, is a 2.5 miles long sealed surfaced traffic-free cycle trail linking the suburban areas to the north east Stafford with the town centre (Figs. 7 and 8). Completed in the autumn of 2005, The Isabel Trail forms part of Route 5

${ }^{2}$ Route 81 to Telford (also known as the Stafford Greenway); Route 5 (North) from Stone and Route 5 (South) from Lichfield providing access to Cannock Chase Forest Park Area of Outstanding Natural Beauty (AONB).

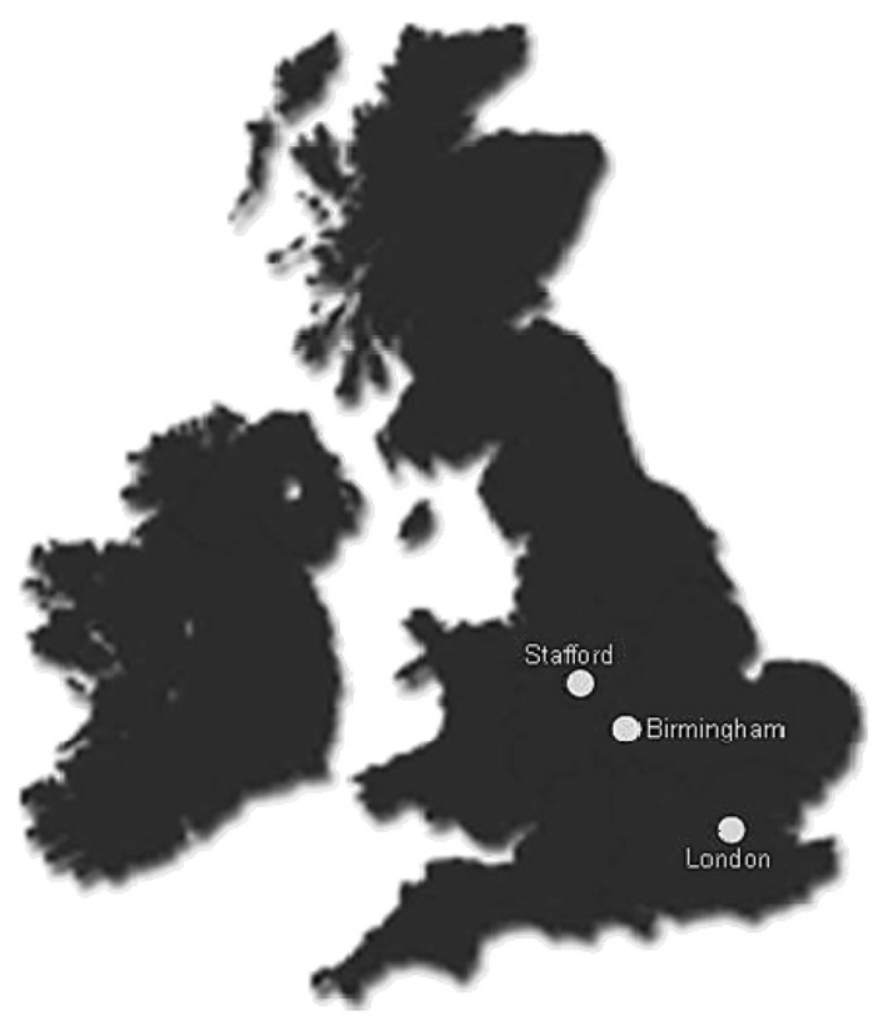

Fig. 5. Location of Stafford in the UK.

of the National Cycle Network and is regarded by the local authority as a 'flagship' route with high potential for replacing short journeys by car with cycling because it removes the danger of motor traffic and provides a direct connection to the town centre from outlying suburbs.

The National Classifications of the 2001 Census Output Area data (Vickers et al., 2005) was initially used to explore demographic profiles of the population within Stafford urban area living adjacent to the Isabel Trail. The Beaconside neighbourhood (Fig. 8) stood out as an established suburban residential area warranting investigation as it is located approximately 2 miles from the town centre at the end of the Trail providing residents with almost entirely traffic-free access to the town centre by bicycle (within a reasonable journey time of around $15 \mathrm{~min}$ ). The neighbourhood is labelled 'Typical Traits' under the National Classification to represent its 'averageness' (i.e. demographic values are neither high nor low in comparison to the other groups in the classification scheme). This classification represents around $15 \%$ of the population of Stafford compared to $18 \%$ of the population of England. The Rickerscote neighbourhood on the southern side of the town some 2 miles from the town centre was selected as a control. This neighbourhood is also labelled 'Typical Traits' under the National Classification scheme but the trafficfree paths that make up the National Cycle Network running through the town are far less accessible to residents living in this area.

A door-to-door drop and collect questionnaire survey was conducted over a period of one month in July 2006 targeting, first, 125 households in Beaconside, and then, 125 households in Rickerscote (Fig. 8). This involved mailing an introductory letter prior to attempting to make personal contact at the doorstep to place questionnaires with adult householders. This approach was preferred to a 'cold' mail-out survey that would have required a much larger sampling frame because of low response rates typically around 10-15\% (see Pooley et al., 2011a, b) and biased 


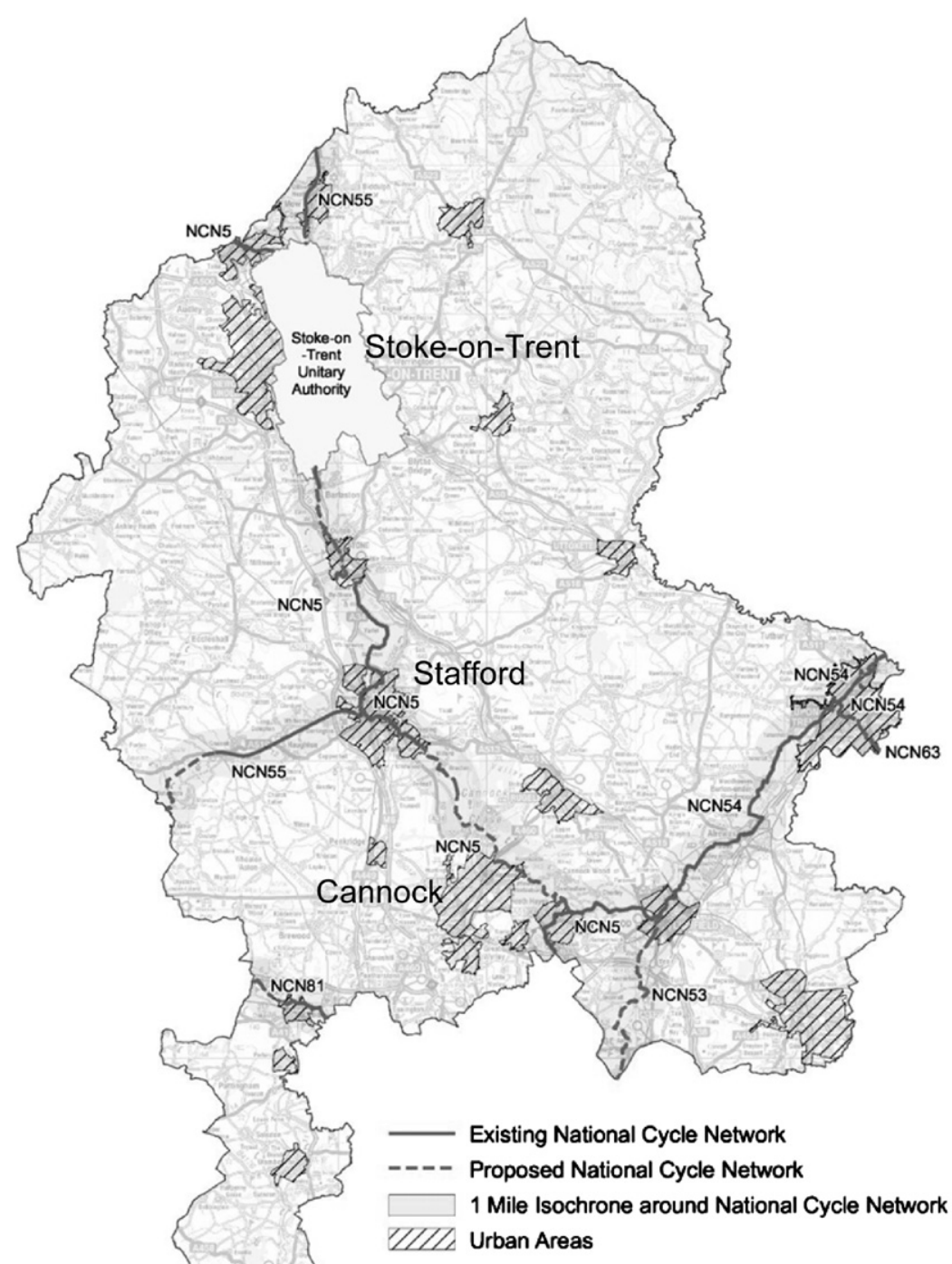

Licensed from Ordnance Survey with the permission of the Controller of Her Majesty's Stationery Office. All rights reserved.

Fig. 6. The National Cycle Network in Staffordshire 2010. Source: Staffordshire County Council.
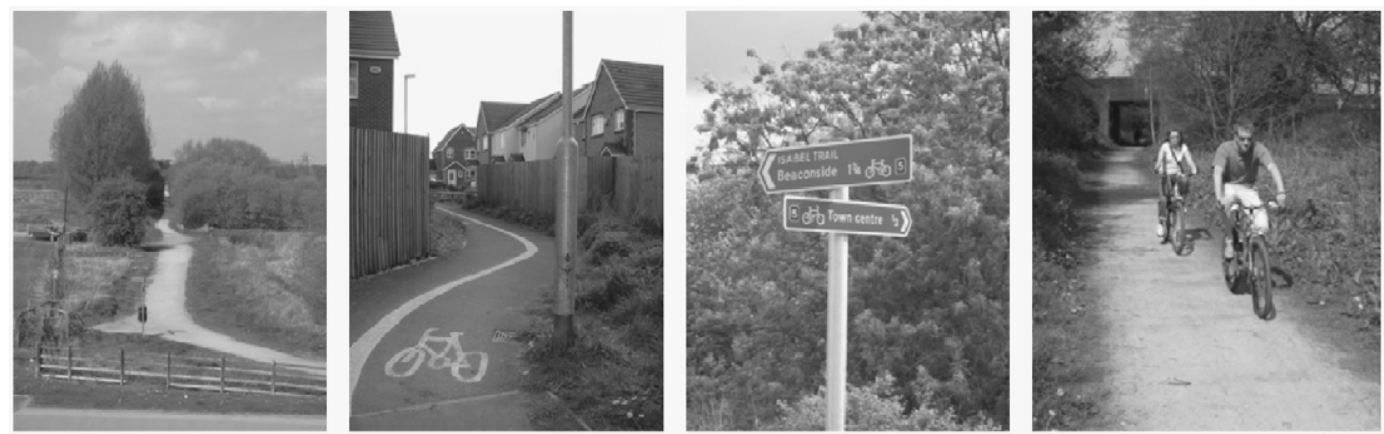

Fig. 7. Photos of The Isabel Trail traffic-free cycle route NCN Route 5 . Source: author's own.

towards those who have an interest in cycling. Furthermore, contact with residents allowed the researcher to make notes on the doorstep from conversations about the subject that naturally arose. The total number of completed questionnaires by adults (aged 17+) at Beaconside was 111 drawn from across 68 households (54\% households surveyed and estimated to represent $47 \%$ of the resident adult population). At Rickerscote (control neighbourhood) a total of 94 questionnaires were completed by adults (aged $17+$ ) drawn from across 60 households (48\% of households surveyed and estimated to represent around $42 \%$ of the resident adult population). The final sample across both neighbourhoods therefore was 205 completed questionnaires (45\% of adult 
population) from adults at 128 households (51\% of sampled households).

The questionnaire placed with householders comprised a A3 folded 10-page booklet containing items that sought to measure current awareness of the available opportunities for traffic-free cycling in the town, use of local traffic-free paths, the share of cycling for local travel for different journey purposes and attitudes to the role of cycling within society and for personal travel. Prospective cycle use was also investigated using the Theory of Planned Behaviour (TPB) (Ajzen, 1985, 1991) as a theoretical framework. The theory is well used in travel behaviour research (see for example Bamberg and Schmidt, 2003a; Bamberg et al., 2003b) and has also been used specifically to comprehend and predict intentions to cycle (Davies et al., 1997; Forward, 1998a, b). The model is based on the premise that individuals go through a systematic process of rationalisation before arriving at a

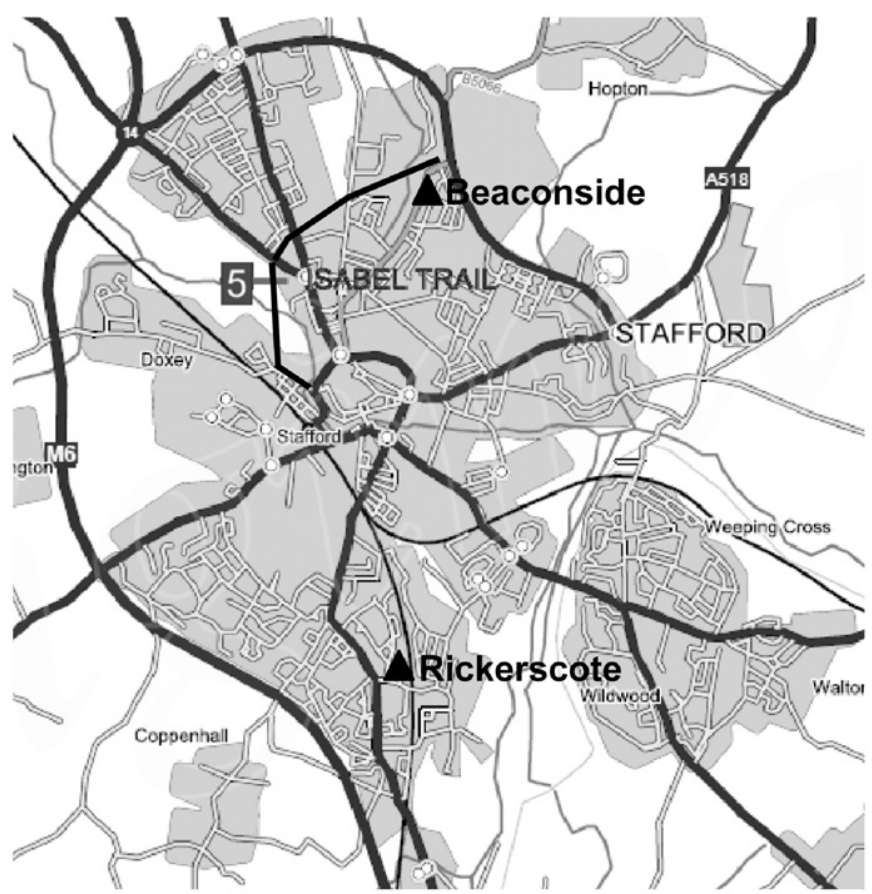

Fig. 8. Alignment of The Isabel Trail (NCN Route 5) and location of surveyed neighbourhoods (Beaconside and Rickerscote). behavioural decision (Fig. 9). The more favourable the attitude (i.e. degree to which carrying out the behaviour by an individual is evaluated positively or negatively), subjective norm (i.e. the perceived social pressure to carry out the behaviour by 'significant others' such as family and friends) and perceived behavioural control (i.e. the individual's perception as to whether they have the ability to perform the behaviour) the stronger the intention to perform the behaviour. To explore the attitude-behaviour connection it is suggested that explicit target behaviour is identified and that this should be defined in terms of target, action, context and time (TACT) (Ajzen, 2002; Francis et al., 2004a). To satisfy this condition, the TPB section of the questionnaire included the following instruction, 'I want you to seriously consider making a journey by cycle from your home to Stafford Town Centre (a distance of approximately 2 miles) on a dry sunny day for practical purposes (e.g. going to a shop) within the next 4 weeks.'

Attitude, subjective norm and perceived behavioural control can be measured both directly and indirectly. Francis et al. (2004b; pp. 46,47) recommend including both measures in TPB questionnaires because direct measures take a generic form that is potentially applicable to a range of behaviours (e.g. cycling is ... good/bad, easy/difficult) and assumes that, 'people have direct access to these evaluations and can accurately give a summary report of an underlying cognitive structure'. In contrast the indirect measures of attitude, subjective norm and perceived behavioural control, 'do not assume that individuals can give a summary estimate of their global attitude' and are only applicable to the behaviour being studied. They are assumed to provide the cognitive and affective foundations i.e. why people hold certain attitudes, subjective norms and perceptions of behavioural control (Ajzen, 2002; p. 7).

All components were measured using statements and 7-point bipolar adjective scales. A direct measure of attitude (evaluative) included one instrumental evaluative item (Undesirable-Desirable) and one experiential evaluative item (Unpleasant-Pleasant). Indirect measures of attitude (beliefs) included ten items covering both evaluative (e.g. reducing my travel time) and affective (e.g. having a relaxing experience whilst travelling) behavioural beliefs about the behaviour and corresponding items measuring the importance of each outcome belief (Outcome Evaluation). Subjective norm (beliefs) included three items tapping perceived approval or disapproval of partner, family and friends' in relation to carrying out the target behaviour and corresponding items measuring motivation to comply with those beliefs. Descriptive

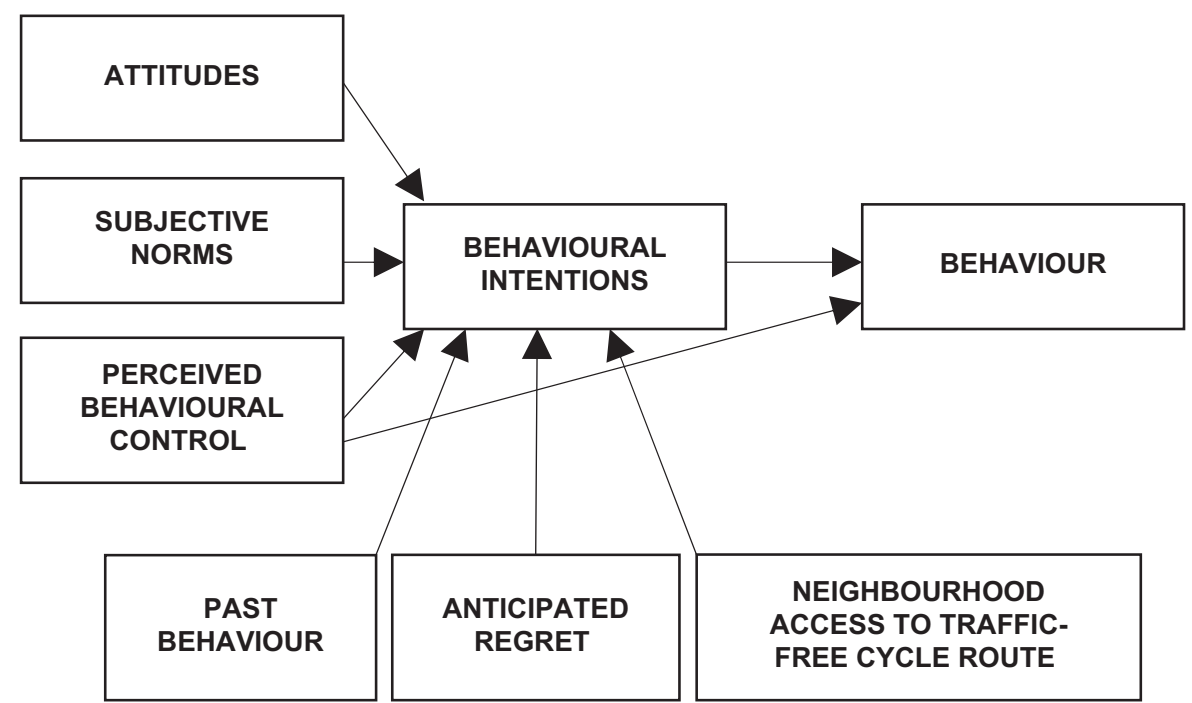

Fig. 9. The (adapted) Theory of Planned Behaviour (Ajzen, 1991). 
norm was also measured by asking respondents to indicate how often significant others (i.e. partner, family and friends) cycled. A direct measure of perceived behavioural control (self-efficacy/controllability) included three items relating to self-efficacy (i.e. perceived personal ability to perform the behaviour) and two to controllability (i.e. whether it would be easy/difficult and possible/ impossible). Indirect measures of perceived behavioural control (beliefs) included items tapping control belief power using four items relating to factors that could make cycling to Stafford more or less likely (e.g. being in a hurry) and control belief strength, the extent to which these factors were likely to facilitate or impede performing the behaviour.

The model was also extended to include two other measures that are suggested to improve predictive ability. These were past behaviour (i.e. self-reported frequency of practical cycling in past month) based on the suggestion that it has an independent influence on future behaviour (Sutton, 1994) and anticipated regret based on regret theory (Bell, 1982; Sheeran and Orbell, 1999; Sandberg and Conner, 2008) which asserts that people attempt to avoid decisions that could result in regret (i.e. "If I did not make at least some journeys by cycle to Stafford town centre for practical purposes, within the next four weeks instead of using other means of transport, I would regret it").

\section{Results}

\subsection{Levels of cycling}

Data was compared between neighbourhoods using nonparametric tests (e.g. Mann-Whitney and Chi-square). Survey analysis revealed that the level of cycling amongst survey respondents living adjacent to the traffic-free path intervention in the neighbourhood of Beaconside was higher than those respondents at the control neighbourhood (Rickerscote). There was a $6 \%$ mode share across all journey purposes for cycling at Beaconside and only $2 \%$ at Rickerscote $(t=2.99, d f=182, p=.003)$ (Table 1, column 1). Travel to work mode share from the 2001 Census also reveals that $7 \%$ of all journey to work were by cycle at Beaconside and only $2 \%$ at Rickerscote suggesting relatively little change in mode share of cycling (at least for the journey to work) since 2001 (Table 1, column 2). This was confirmed by asking respondents to indicate on a five point scale (i.e. +2 'increased' to -2 'decrease' with zero 'no change') how overall use of different modes used had changed over the previous 12 months (i.e. prior to the NCN traffic-free path being implemented). This indicated that levels of cycle use were perceived to have declined slightly across both neighbourhoods whilst walking and car driving had increased slightly (Fig. 10). Overall this suggests that levels of cycling had not increased since the traffic-free intervention was completed in November 2005.

Table 1

Reported cycling mode share compared to Census 2001 Travel To Work (TTW).

\begin{tabular}{|c|c|c|}
\hline & $\begin{array}{l}\text { Proportion cycling } \\
\text { mode share across all } \\
\text { journey purposes }\end{array}$ & $\begin{array}{l}2001 \text { Census } \\
\text { Travel To Work } \\
\text { mode proportion }\end{array}$ \\
\hline England and Wales & - & 2.76 \\
\hline Stafford & - & 3.15 \\
\hline $\begin{array}{l}\text { Beaconside (access to } \\
\text { traffic-free routes) }\end{array}$ & 6 & 7 \\
\hline \multirow{2}{*}{$\begin{array}{l}\text { Rickerscote (limited } \\
\text { access to traffic-free } \\
\text { routes) }\end{array}$} & 2 & 2 \\
\hline & $t=2.99, d f=182, p=.003$ & \\
\hline
\end{tabular}

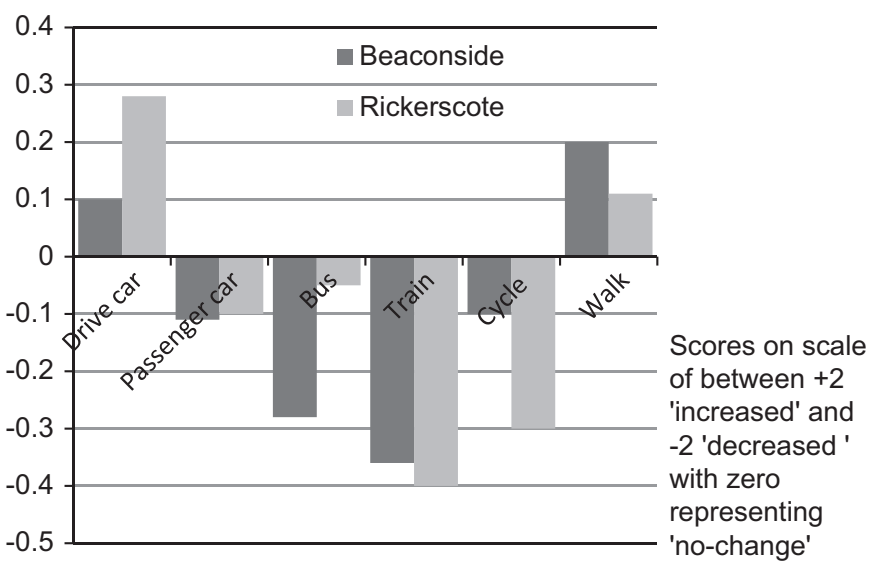

Fig. 10. Perceived changes in travel behaviour over last 12 months.

\subsection{Familiarity with opportunities for traffic-free cycling}

Familiarity with the availability of the NCN Route 5 Isabel Trail traffic-free path was investigated. There was a significant difference between sites with $59 \%$ of respondents at Beaconside familiar with this facility compared with only $6 \%$ at Rickerscote $\left(X^{2}=71.1, d f=2, p<.001\right)$. This would suggest that proximity to traffic-free facilities appears to increase awareness of opportunities for traffic-free cycling. However, the comments of one respondent at Beaconside revealed the potential lack of awareness of other opportunities for traffic-free cycling across Stafford: "I use the Isabel Trail a lot but was surprised to find out there was two others [traffic-free routes] in Stafford. May be these would be used more if better publicised?" (Male, age 41). Although familiarity with the National Cycle Network was higher at Beaconside (30\%) compared to Rickerscote (18\%) there was no statistically significant difference between neighbourhoods $\left(X^{2}=3.14, d f=1\right.$, $p=.08$ ). Furthermore, around $90 \%$ of respondents in each neighbourhood were not familiar with Sustrans, the organisation behind the development of the NCN. This suggests that proximity to NCN facilities does not guarantee increased awareness of 'the Sustrans mission' (i.e. to encourage a mode shift from car use to walking and cycling). It would appear, therefore, that increased effort is required at the local level to disseminate promotional messages about the availability of the National Cycle Network and the opportunities it provides to replace short car journeys with cycling (and walking).

\subsection{Actual use of traffic-free routes and perceived effect on level and type of cycling}

When comparing use of traffic-free routes for cycling between neighbourhoods (Fig. 11), around 20\% $(n=21)$ respondents at the Beaconside neighbourhood reported using traffic-free routes in Stafford at least once a month compared to only $5 \%(n=6)$ at the control site $\left(X^{2}=14.75, d f=3, p=.002\right)$. This result is statistically significant and seems to suggest that the availability of a nearby traffic-free cycling route is encouraging cycling. Almost all respondents who reported ever having used the route for cycling (i.e. including those who did so less than monthly) did so mainly for recreation whereas only around one third used the route for the journey to work or other practical journey purposes such as shopping (Table 2). This suggests that the provision of the trafficfree facility has provided an important near-to-home recreational cycling facility (for at least one fifth of the population of Beaconside) but that the facility is less significant in supporting everyday practical journeys by cycle. It is also unclear whether these are additional recreational journeys or whether they are replacing 


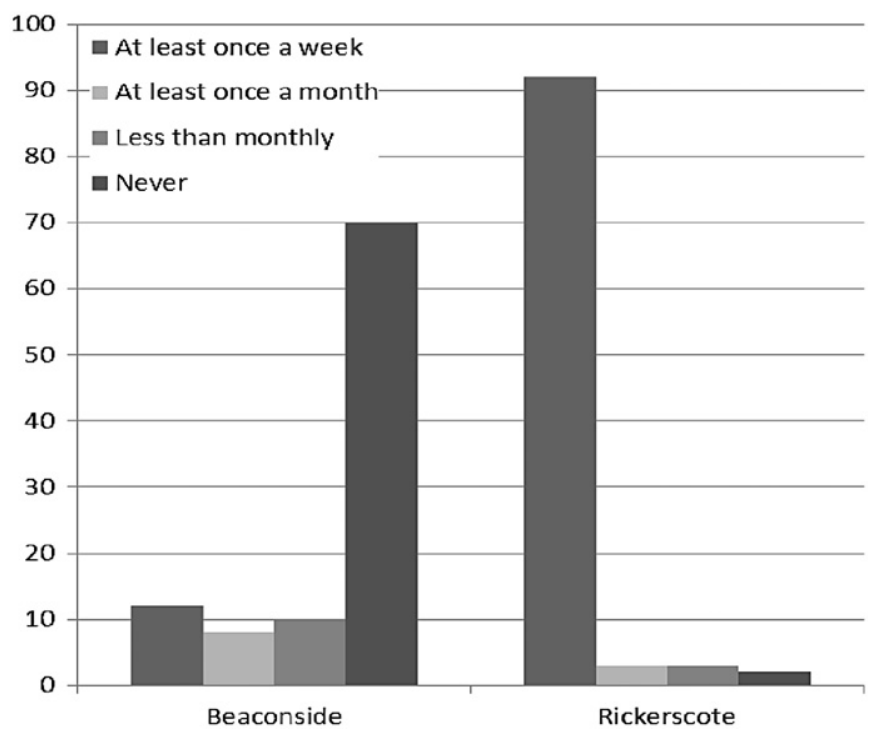

Fig. 11. Use of traffic-free cycle routes in Stafford.

Table 2

Purposes for which residents of Beaconside use the Isabel Trail traffic-free route.

\begin{tabular}{lc}
\hline Rank ordered reported use of traffic-free path for ... & Percent \\
\hline Local recreational journeys & 96 \\
Journey to work & 32 \\
Light grocery shopping & 32 \\
Visiting friends and relatives & 24 \\
Travel to (Stafford) High Street & 20 \\
Journey to school & 16 \\
Heavy food shopping & 4 \\
\hline
\end{tabular}

\section{Practical cycling}

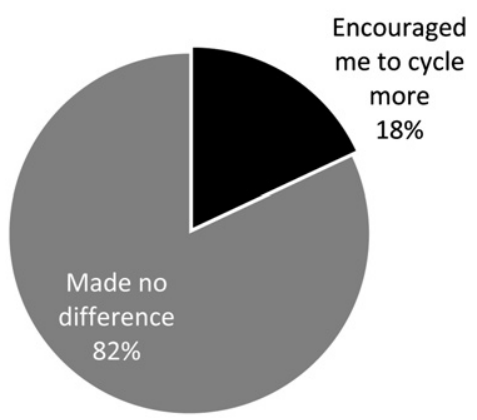

Recreational cycling

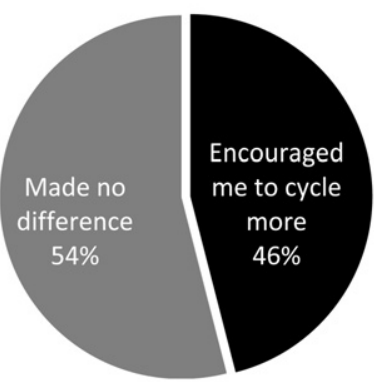

Fig. 12. Effect of traffic-free path on cycle users at Beaconside on practical and recreational cycling.

recreational journeys that would have otherwise been made by car.

Respondents $(n=111)$ at the Beaconside site were asked to report the perceived effect of the availability of the Isabel Trail traffic-free route on their level and type of cycling. Around one third $(n=33)$ reported ever having used the route for cycling, and of those people, only around one fifth $(n=6)$ stated that they had been encouraged to cycle more for practical journeys and around one half $(n=15)$ for recreational journeys, again confirming the importance of the facility as a local recreational offering (Fig. 12). When considering this as a proportion of the total population at the Beaconside neighbourhood (i.e. including those that reported never having used the facility), less than $5 \%$ of the total population in the Beaconsfield neighbourhood sampled report having been encouraged to cycle more for practical purposes and $14 \%$ for leisure as a result of availability of the traffic-free path.

It was highlighted earlier that one assumption is that NCN traffic-free routes provide the opportunity for less experienced cyclists to gain the confidence and experience necessary to enable them to cycle more. This was tested by asking respondents living adjacent to the NCN at Beaconside their level of agreement or disagreement with the statement, 'Using the traffic-free cycle path has given me the skills and confidence to cycle in a variety of different contexts including riding on the road mixing with traffic'. Only 5 of the 33 people who reported ever having used the route, agreed with this statement. This represents less than $5 \%$ of the total sample population at Beaconside and suggests that there is little evidence that providing near-to-home traffic-free free cycling opportunities encourages cycling in different environmental contexts such as on the road mixing with general traffic.

\subsection{Future intention to cycle for short practical journeys}

Fig. 13 shows the level of agreement and disagreement with the statement, "Within the next four weeks I plan to make a cycle journey to Stafford town centre for practical purposes...", and demonstrates the low level of intention to cycle for practical purposes at both neighbourhoods. Around $80 \%$ of respondents at Beaconside and $90 \%$ of respondents at Rickerscote stated that they did not intend to make a practical journey by cycle to Stafford town centre during the following four weeks and the difference between these values was not significant different $(t=1.76, d f=190, p<.08)$.

The Theory of Planned Behaviour (Ajzen, 1985, 1991) described earlier was used to explore attitudes to cycling and predict respondents' intention to cycle with the relevant components of the theoretical model including past behaviour, anticipated regret and neighbourhood (see Fig. 8 earlier). Multinomial logistic regression was used as the tool of analysis because it does not assume that the relationship between the independent variables and the dependent variable is a linear one or that the dependent variable or residuals are distributed normallyassumptions violated by this data-and is more robust when these assumptions are not met (Hair et al., 1998; p. 276). Multinomial logistic regression is also used where there are three or more categorical outcome variables and provides estimates of the probability of each outcome occurring based on changes to significant independent variables in the model. Due to low sample size the analysis was performed on aggregated data for all respondents $(n=205)$ from across both neighbourhoods (i.e. Beaconside and Rickerscote) and the five-point scale of the

"Within the next four weeks I plan to make a cycle journey to Stafford town centre for practical purposes..."

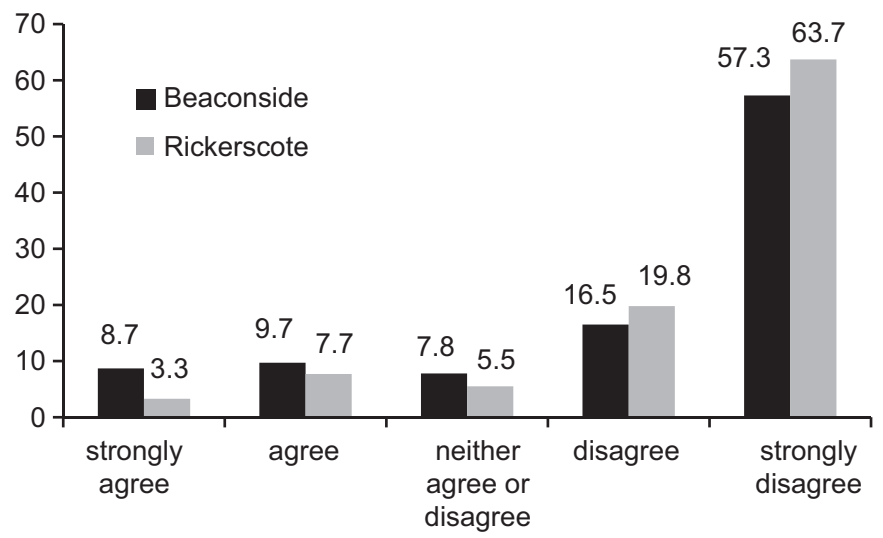

Fig. 13. Intention to make a practical cycle journey to Stafford town centre. 
intention variable was split into three categories representing 'no intention' (previous score $=1$ ), 'low-intention' (previous score $=2$ or 3 ) and 'moderate to high intention' (previous score $=4-5$ ) in order to adequately populate each category (Table 3 ).

The 'low intention' category was chosen as the reference group when performing the analysis so that the regression was able to demonstrate which variables are significantly predictive of being

Table 3

Case summaries for 3 category dependent variable (intention) used in multinomial logistic regression analysis.

\begin{tabular}{lrl}
\hline $\begin{array}{l}\text { Intention to make a practical cycle journey from home to } \\
\text { town centre (approx. 2 miles) within next 4 weeks. }\end{array}$ & $\begin{array}{l}\text { Marginal } \\
\text { Percentage }\end{array}$ \\
\hline No intention & 117 & 60.3 \\
Low intention & 45 & 18.0 \\
Moderate to high intention & 103 & 53.1 \\
Beaconside (direct access to traffic-free route) & 91 & 46.9 \\
Rickerscote (no direct access to traffic-free route) & 194 & 100 \\
Valid & 11 & \\
Missing & 205 & \\
Total & \multicolumn{2}{l}{} \\
\end{tabular}

Table 4

Classification table showing ability of model to predict group membership.

\begin{tabular}{|c|c|c|c|c|}
\hline \multirow[t]{2}{*}{ Observed } & \multicolumn{4}{|l|}{ Predicted } \\
\hline & $\begin{array}{l}\text { No } \\
\text { intention }\end{array}$ & $\begin{array}{l}\text { Low } \\
\text { intention }\end{array}$ & $\begin{array}{l}\text { Moderate/High } \\
\text { intention }\end{array}$ & $\begin{array}{l}\text { Percent } \\
\text { correct }\end{array}$ \\
\hline No intention & 108 & 3 & 6 & 92.3 \\
\hline Low intention & 15 & 12 & 8 & 34.3 \\
\hline $\begin{array}{l}\text { Medium/High } \\
\text { intention }\end{array}$ & 2 & 10 & 20 & 47.6 \\
\hline $\begin{array}{l}\text { Overall } \\
\text { percentage (\%) }\end{array}$ & 69.6 & 12.9 & 17.5 & 72.2 \\
\hline
\end{tabular}

in either of the extreme categories (i.e. 'no-intention' and 'moderate/high intention') compared with the middle category of 'lowintention'. Several models were tested but the best model fit specification included all of the independent variables including neighbourhood. The final model outperforms the intercept only (null) model and is statistically significant $\left(\chi^{2}=121.598, d f=18\right.$, $p<.001)$. The existence of a relationship between the independent variables and the dependent variable was therefore supported (i.e. the null hypothesis that there was no difference between the model without independent variables and the model with independent variables was rejected). Table 4 shows that the model provides better predictive ability for 'no-intention'.

The strength of the relationship indicated by the Pseudo $R^{2}$ (Nagelkerke) value was .549 which suggests that the proportion of variation being explained by the model is 55\%. The overall likelihood ratio test revealed that there is a statistically significant relationship between the dependent variable intention to cycle for a short practical journey and subjective norm $\left(\chi^{2}=6.18, d f=2\right.$, $p<.05)$, self-efficacy/controllability $\left(\chi^{2}=7.21, d f=2, p<.05\right)$, past behaviour $\left(\chi^{2}=8.48, d f=2, p<.05\right)$ and also anticipated regret $\left(\chi^{2}=23.25, d f=2, p<.001\right)$. Neighbourhood, however, was not a significant predictor of intention to cycle.

The model summary reproduced in Table 5 below demonstrates that anticipated regret is significant in distinguishing the 'no-intention' category of the dependent variable from the 'low intention' category of the dependent variable (Wald $=19.83$, $d f=2, p<.001$ ). Self-efficacy/controllability is also significant in distinguishing the 'no-intention' category of the dependent variable from the 'low intention' category of the dependent variable (Wald $=4.93, d f=2, \quad p<.05$ ) and also descriptive norm (Wald $=3.94, d f=2, p=.05$ ). None of the independent variables in the model including site were significant in distinguishing the 'moderate-high' intention category from the 'low intention' category. Whilst, past behaviour came closest this was not sufficiently significant at the $95 \%$ level of confidence $(p=.06)$.

The $\operatorname{Exp}(B)$ statistic in Table 5 is an indicator of the change in odds resulting from a unit change in the predictor variable. If the

Table 5

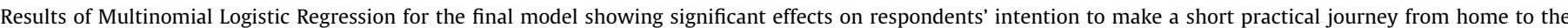
town centre.

\begin{tabular}{|c|c|c|c|c|c|c|c|c|}
\hline \multirow{2}{*}{$\begin{array}{l}\text { Intention to make a practical journey by cycle from home } \\
\text { to the town centre within the next four weeks. }\end{array}$} & \multirow[t]{2}{*}{ B estimate } & \multirow[t]{2}{*}{ SE } & \multirow[t]{2}{*}{ Wald } & \multirow[t]{2}{*}{$d f$} & \multirow[t]{2}{*}{$p(\mathrm{Sig})$} & \multirow[t]{2}{*}{$\operatorname{Exp}(B)$} & \multicolumn{2}{|c|}{ 95\% Confidence Interval $\operatorname{Exp}(B)$} \\
\hline & & & & & & & Lower bound & Upper bound \\
\hline \multicolumn{9}{|l|}{ No intention } \\
\hline Intercept & 6.248 & 1.251 & 24.957 & 1 & .001 & - & - & - \\
\hline Attitude (beliefs) & -.192 & .184 & 1.081 & 1 & .298 & .826 & .575 & 1.185 \\
\hline Attitude (evaluative) & .034 & .065 & .278 & 1 & .598 & 1.035 & .911 & 1.176 \\
\hline Subjective norm (beliefs) & -.070 & .056 & 1.552 & 1 & .213 & .933 & .836 & 1.041 \\
\hline Descriptive norm & -1.366 & .697 & 3.939 & 1 & .050 & .255 & .065 & 1.000 \\
\hline Perceived behavioural control (beliefs) & .039 & .042 & .873 & 1 & .350 & 1.040 & .958 & 1.129 \\
\hline Self-efficacy controllability & -.408 & .184 & 4.928 & 1 & .026 & .665 & .464 & .953 \\
\hline Anticipated regret & -.732 & .164 & 19.831 & 1 & .001 & .481 & .348 & .664 \\
\hline Past (cycling) behaviour & -3.341 & 4.830 & .478 & 1 & .489 & .035 & $2.74 \mathrm{E}-006$ & 457.656 \\
\hline Neighbourhood = Beaconside/Rickerscote & .444 & .522 & .725 & 1 & .394 & 1.560 & .561 & 4.337 \\
\hline \multicolumn{9}{|l|}{ Moderate to high intention } \\
\hline Intercept & .437 & 1.325 & .109 & 1 & .741 & - & - & - \\
\hline Attitude (beliefs) & .056 & .072 & .603 & 1 & .437 & 1.058 & .918 & 1.219 \\
\hline Attitude (evaluative) & -.074 & .202 & .135 & 1 & .714 & .929 & .626 & 1.379 \\
\hline Subjective norm (beliefs) & .060 & .056 & 1.160 & 1 & .281 & 1.062 & .952 & 1.186 \\
\hline Descriptive norm & -.509 & .600 & .718 & 1 & .397 & .601 & .185 & 1.950 \\
\hline Perceived behavioural control (beliefs) & -.014 & .045 & .098 & 1 & .754 & .986 & .904 & 1.076 \\
\hline Self-efficacy/controllability & -.025 & .209 & .015 & 1 & .903 & .975 & .647 & 1.469 \\
\hline Anticipated regret & -.189 & .155 & 1.483 & 1 & .223 & .828 & .611 & 1.122 \\
\hline Past (cycling) behaviour & 6.326 & 3.379 & 3.505 & 1 & .061 & 558.767 & .743 & 420111.205 \\
\hline Neighbourhood $=$ Beaconside/Rickerscote & .314 & .538 & .340 & 1 & .560 & 1.369 & .477 & 3.928 \\
\hline
\end{tabular}

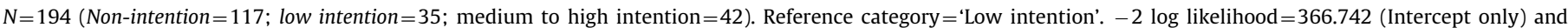
245.144 (Final). Model Chi-square $=121.598 ; d f=18 ; p<.001$; Pseudo $R^{2}$ (Nagelkerke) $=.55$. 
value is greater than 1 , then as the predictor increases, the odds of the outcome occurring increases. Conversely, a value less than one indicates that, as the predictor increases, the odds of the outcome occurring decrease. This suggests the following:

1. For each unit increase in self-efficacy/controllability the odds of being in the group of survey respondents who indicated that they had no intention of making a practical journey from home to the town centre by bicycle decreases by $36.5 \%$ (i.e. .635-1).

2. For each unit increase in anticipated regret the odds of being in the group of survey respondents who indicated that they had no intention of making a practical journey from home to the town centre by bicycle decreases by $48.8 \%$ (i.e. .512-1).

3. For each unit increase in descriptive norm the odds of being in the group of survey respondents who indicated that they had no intention of making a practical journey from home to the town centre by bicycle decreases by $74.5 \%$ (i.e. .255-1).

In summary, the odds of a respondent making a practical journey by bicycle increases if other family members cycle, and if there would be a feeling regret if the journey was not made by cycle; and when, on balance, there is a belief in personal ability to make a practical journey by cycle (self-efficacy) and/or a perception that this journey is both possible and easy (controllability). The regression analysis revealed that neighbourhood (i.e. Beaconsfield/Rickerscote) did not add to the predictive ability of the model and its contribution is therefore not significant. This suggests that householders with direct access to traffic-free cycle facilities outside their homes are no more likely to make practical journeys by cycle than those householders without direct access to such facilities.

Some of the comments received during the doorstep surveys might explain the lack of engagement with traffic-free interventions and the apparent attitude-behaviour gap in terms of replacing journeys by car with cycling. As one female respondent (aged 33) candidly expressed, “Generally speaking, I guess I could say that I don't practice what I preach. The principles behind methods of green travel are important to me and I understand them greatly. If I was to be honest I would say that it is easier to use my car, more convenient perhaps". Even where there is a desire to cycle the wider transport system where journeys inevitably have to take place in order to reach everyday activities is not perceived as supportive as one survey respondent (male aged 37 years) clearly expressed, "I would like to cycle more but I find the roads dangerous and the cycle lanes in Stafford more often than not do not go anywhere. If cycling is going to ever be an alternative then there must be cycle lanes on the majority of roads like I have seen on the Continent in Holland and Denmark".

\section{Discussion}

The focus of this paper has been a significant policy intervention aimed at increasing levels of cycling in the UK and generating a cycling culture. The National Cycle Network developed by Sustrans is supported by national government and local authorities on the premise that it will bring benefits in terms of traffic reduction, improvements to health, improved economic prospects, inclusive travel opportunities and a safer travelling environment. The proposition by Sustrans that providing at least one high quality traffic-free route in every urban area can persuade people to cycle again, and in doing so, convince them that cycling is a valuable and appropriate means of transport for short journeys was tested.

Evidence produced by Sustrans reveals that around two-thirds of all trips by bicycle on the Network take place on traffic-free routes and that these sections have witnessed the most growth. However, this paper highlighted that the evidence base is characterised by large aggregate datasets and that there is a paucity of evidence of the impacts of localised traffic-free path interventions on the communities they serve. By focusing on a single case study location where such interventions have been implemented (and where significant perceived barriers to cycling such as difficult topography and traffic danger either do not exist or have been removed) this study was able to identify whether the provision of a good length of flat traffic-free cycle route, linking the urban centre to the suburbs (a distance of around 2 miles), has generated a cultural response to cycling and promoted more sustainable travel behaviour.

The key finding is that provision of National Cycle Network urban traffic-free cycle routes alone would appear to be insufficient in encouraging a shift from car travel to cycling for everyday practical journeys. Although it was revealed that there is a higher rate of cycling across all journey purposes at Beaconside where the traffic-free intervention has been implemented, there was little evidence that the availability of the traffic-free path was the main causal factor. It is more likely that this was the result of other environmental and social-psychological variables (e.g. proximity of journey attractors, individual cycling experience/skill and desirability of cycling amongst householders vis-à-vis travelling by car) that would need to be established through further study.

Whilst residential proximity to urban traffic-free routes does not necessarily increase levels of cycling for everyday travel there is strong evidence that it can help to facilitate near-to-home recreational opportunities-nearly one third of the population living adjacent to the traffic-free route at Beaconside reportedly used the Isabel trail for recreational cycling. In this respect, neighbourhoods with good access to Sustrans type traffic-free routes are best placed to take advantage of demand for nearhome recreational opportunities. However, it should be noted that, proximity to a section of National Cycle Network urban traffic-free trail does not automatically increase levels of awareness of the either the NCN concept or of the Sustrans 'brand'. Indeed, awareness of Sustrans and the National Cycle Network was very low even amongst residents living adjacent to the NCN. This suggests that there is plenty of scope to market the benefits that NCN traffic-free facilities have to offer amongst UK households served directly by such facilities.

It is also worth noting the comments made during doorstep surveys with residents who already cycle which suggests that they value the additional route option provided by the local traffic-free paths, but were also keen to see supportive on-highway measures along the existing road network that connects them more directly with their everyday activities. Women in particular expressed concern about using traffic-free paths because of feelings of isolation in comparison to the relative perception of security whilst moving amongst other bodies on or alongside the general highway network. There are important lessons for policy makers here. As commented in the earlier section of this article, often route provision away from the highway is a more politically palatable option vis-à-vis re-allocating (or re-appropriating) scarce road-space to cycling (or walking and public transport for that matter). However, the findings of this study demonstrate (at least for the case study in question) that traffic-free paths away from the public highway are, at best, successful in encouraging cycling within a specific context i.e. recreational riding (often 'together' and family oriented). There is little evidence to suggest that this is translating into everyday cycling.

Encouraging recreational cycling is a worthy outcome in itself in terms of promoting health and social wellbeing but is limited in terms of creating a culture change in everyday travel whilst the car is a more convenient and competitive option for moving around the city and the general highway network remains hostile to cycling. This suggests that a broader multi-faceted approach to 
promoting practical everyday cycling is required (Pucher and Buehler, 2008). More specifically, provision of good quality separate cycling facilities alongside heavily travelled roads and linking to everyday facilities that people need to use, self-enforcing speed restrictions using traffic calming and more intelligent design across residential neighbourhoods, coupled with making driving expensive and inconvenient in central urban areas through various restrictions on car use and car parking. Encouraging the public onto the 'nursery slopes' of Sustrans style trafficfree paths in order to acquire the skills for cycling on the road network for everyday purposes seems unlikely to create a mass modal shift away from journeys by car.

\subsection{Limitations of this study}

There is a general paucity of evidence which demonstrates that developing or altering transport infrastructure or other aspects of the built environment have led to an increase in walking or cycling or a modal shift away from car use. Badland and Schofield (2005; p. 192) have noted in a meta-analysis of existing studies, that the majority of existing research on the association between the built environment and physical activity behaviour is based on 'countryspecific, self-report cross-sectional designs, which have led to inherent flaws and no establishment of causality'. This research falls into that trap-although the focus of this study was the effect of an environmental intervention on travel behaviour. Therefore, it is difficult to attribute causality-that the traffic-free routes causes more people to cycle that otherwise would not have cycled.

Indeed, there is genuine difficulty applying robust study designs to the evaluation of complex infrastructural interventions. As well as availability of cycling infrastructure such as traffic-free trails, other objective environmental variables such as connectivity, land use mix and transport system characteristics could be important factors affecting whether the population chooses to cycle, not to mention psychological, social and cultural factors. There is a need, therefore, to develop more sophisticated 'ecological' models of behaviour which take into consideration a host of possible explanatory variables covering the physical environment and the psycho-socio-cultural milieu of the individual (Saelens et al., 2003).

Ideally, this research could have used a test re-test experimental research design to measure travel behaviour at Beaconside (the intervention neighbourhood) and at Rickerscote (the control neighbourhood) prior to intervention and again after intervention to measure any effect. Future studies should aim to use a classic pre-test post-test experimental design to obtain more reliable evidence of the effects of environmental interventions targeted at encouraging everyday cycling. Longitudinal surveys of communities served by new interventions targeted at encouraging cycling can also be used to monitor awareness and changes in attitudes and behaviour using more in-depth qualitative techniques at the household level. A further project of nationwide interventions to encourage walking and cycling being developed by Sustrans, the Connect $2^{3}$ project, offers an excellent opportunity to implement this type of study.

\section{Conclusion}

The study discussed in this paper set out to understand the localised effects of typical Sustrans style traffic-free path

\footnotetext{
${ }^{3}$ In December 2007 Sustrans' Connect2 UK-wide project won the public vote in the Big Lottery Fund's The People’s $£ 50$ Million. The project aims to revitalise walking and cycling in 79 communities across the UK by creating new routes for local journeys. Crossings and bridges will be created over busy roads, railway lines and rivers, linking into new networks of local paths.
}

interventions on cycling for everyday travel. The key finding is that, provision of significant lengths of National Cycle Network urban traffic-free cycle routes alone, appear to be insufficient in encouraging a shift from car travel to cycling for everyday practical journeys. Urban traffic-free paths were found to be significant, however, in facilitating near-to-home recreational cycling. This suggests that a wider co-ordinated multi-faceted approach to promoting cycling is required which combines social marketing with physical measures including wider speed restrictions in urban areas, investment in high quality segregated cycle facilities along main urban street corridors and general land use and transport policies that 'advantage cycling' and reduce the convenience of the car. The difficult question is how to make this politically acceptable.

\section{Acknowledgements}

Thank you to Peter Headicar and Mary Sissons Joshi (Oxford Brookes) for their support throughout this research and to Staffordshire County Council and Sustrans for permission to use materials.

\section{References}

Ajzen, I., 1985. From intentions to actions: A theory of planned behaviour. In: Kuhl, J., Beckmann, J. (Eds.), Action-Control: From cognition to behaviour. Springer, Hiedelberg.

Ajzen, I., 1991. The theory of planned behaviour. Organisational Behaviour and Human Decision Processes 50, 179-211.

Ajzen, I. (2002) Constructing a TPB Questionnaire: Conceptual and Methodological Considerations. Available at: 〈http://people.umass.edu/aizen/tpb.html $\rangle$ (Accessed: 22 May 2004)

Badland, H., Schofield, G., 2005. Transport, urban design, and physical activity: an evidence-based update. Transportation Research Part D: Transport and Environment 10 (3), 177-196.

Bamberg, S., Schmidt, P., 2003a. Incentives, morality, or habit? Predicting students car use for university routes with the models of Ajzen, Schwartz and Triandis'. Environment and Behaviour 35 (2), 264-285.

Bamberg, S., Ajzen, I., Schmidt, P., 2003b. Choice of travel mode in the theory of planned behavior: the roles of past behavior, habit, and reasoned action. Basic and Applied Social Psychology 25 (3), 175-187.

Bauman, A., 2005. The physical environment and physical activity: moving from ecological associations to intervention evidence. Journal of Epidemiology and Community Health 59, 535-536.

Bell, D.E., 1982. Regret in decision making under uncertainty. Operations Research 21, 961-981.

Cope, A., Cairns, S., Fox, K., Lawlor, D.A., Lockie, M., Lumsdon, L., Riddoch, C., Rosen P., 2003. The UK National Cycle Network: An Assessment of the Benefits of a Sustainable Transport Infrastructure. World Transport Policy and Practice 9 (1), 6-17

Davies, D.G., Halliday, M.E., Mayes, M. \& Pocock, R.L. (1997) Attitudes to Cycling: A Qualitative Study and Conceptional Framework. TRL Report 266. Crowthorne: Transport Research Laboratory.

Department for Transport, 2004. Walking and Cycling: An Action Plan. The Stationery Office, London.

Department for Transport, 2006. Transport Statistics Bulletin - National Travel Survey: 2006. TSO, London.

Department for Transport, 2007a. Personal Travel Factsheet January 2007-Cycling. Department for Transport, London.

Department for Transport, 2007b. A Sustainable Future For Cycling. Department for Transport, London.

Department for the Environment, Food and Rural Affairs, 2008. A Framework for Pro-Environmental Behaviours Report January 2008. Department for the Environment, Food and Rural Affairs, London.

Flyjberg, B., 2001. Making Social Research Matter: Why Social Inquiry Fails and How it Can Succeed Again. Cambridge University Press.

Forester, J., 2001. The Bikeway Controversy. Transportation Quarterly 55 (2) Spring 2001.

Forward, S.E., 1998a. Behavioural Factors Affecting Modal Choice: ADONIS Swedish National Road and Transport Research Institute, Sweden.

Forward, S.E., 1998b. Modes of Transport on Short Journeys. Attitudes and Behaviour of inhabitants of Gothenberg. Swedish National Road and Transport Research Institute.

Francis, J.J., Eccles, M.P., Johnston, M., Walker, A., Grimshaw, J., Foy, R., Kaner, E.F.S. Smith, L., Bonetti, D., 2004a. Constructing Questionnaires Based On The Theory Of Planned Behaviour: A Manual for Health Service Researchers. Centre for Health Services Research, University of Newcastle. 
Francis, J.J., Eccles, M.P., Johnston, M., Walker, A., Grimshaw, J. Foy, R., Kaner, E.F.S., Smith, L. \& Bonetti, D. (2004b) Measurement Issues in the Theory of Planned Behaviour: A Supplement to the Manual for constructing questionnaires based on the Theory of Planned Behaviour. Appendix C: Discussion Paper. University of Newcastle: Centre for Health Services Research.

Hair, J.F., Anderson, R.E., Tatham, R.L., Black, W.C., 1998. Multivariate Data Analysis. 5th Edition. Prentice Hall, New Jersey.

Lawlor, D.A., Ness, A.R., Cope, A.M., Davis, A., Insall, P., Riddoch, C., 2003. The Challenges of Evaluating Environmental Interventions to Increase the Population Levels of Physical Activity: The Case of the UK National Cycle Network. Journal of Epidemiology and Community Health 57 (96), 96-101.

Mackett, R., 2003. Why do people use their cars for short trips? Transportation 30 (3), 329-349.

Parkin, J., Ryley, T., Jones, T.D., 2007. Barriers to Cycling: An Exploration of Quantitative Analyses. In: Horton, D., Rosen, P., Cox, P. (Eds.), Cycling and Society. Ashgate, Aldershot.

Pooley, C.G., Tight, M., Jones, T., Horton, D., Scheldeman, G., Jopson, A., Mullen, C. Chisholm, A., 2011a. Understanding Walking and Cycling: summary of key findings and recommendations. Lancaster University.

Pooley, Colin G., Horton, D., Scheldeman, D., Tight, M., Jones, T., Chisholm, A Harwatt, H., Jopson, A., 2011b. Household decision-making for everyday travel: a case study of walking and cycling in Lancaster (UK). Journal of Transport Geography (aip).

Pucher, J., Dijkstra, L., 2000. Making walking and cycling safer: lessons from Europe. Transportation Quarterly 54, 3.

Pucher, J., 2001. Cycling safety on bikeways v roads. Transportation Quarterly 55,4 .
Pucher, J., Buehler, R., 2008. Making Cycling irresistible: lessons from The Netherlands, Denmark and Germany. Transport Reviews 28 (4), 495-528.

Saelens, B., Sallis, J., Frank, L., 2003. Environmental correlates of walking and cycling: findings from the transportation, urban design and planning literatures. Annals of Behavioral Medicine 25 (2), 80-91.

Sandberg, T., Conner, M., 2008. Anticipated regret as an additional predictor in the theory of planned behaviour: A meta-analysis. British Journal of Social Psychology 47 (4), 589-606.

Sheeran, P., Orbell, S., 1999. Augmenting the theory of planned behavior: roles for anticipated regret and descriptive norms. Journal of Applied Social Psychology 29 (10), pp. 2107-2142.

Sloman, L., 2006. Car Sick: Solutions for Our Car Addicted Culture. Green Books Ltd, Totness.

Stake, R.E., 2000. The case study method in social inquiry. In: Gomm, R., Hammersley, M., Foster, P. (Eds.), Case Study Methods: key issues, key texts. Sage, London.

Sustrans, 2006. The National Cycle Network Route User Monitoring Report to End of 2005. Sustrans, Bristol.

Sustrans (2011) Solutions for Life: Annual Review 2010. Sustrans, Bristol.

Sutton, S., 1994. The past predicts the future: Interpreting behaviour-behaviour relationships in social-psychological models of health behaviours. In: Rutter, D.R., Quine, L. (Eds.), Social Psychology and Health: European Perspectives. Aldershot, Avesbury, pp. 71-88.

Vickers, D., Rees, P. and Birkin, M. (2005) Creating the National Classification of Census Output Areas: Data, Methods and Results. Working Paper 05/02, School of Geography, University of Leeds.

Wickers, D., 2000. Millennium Miles: The Story of the National Cycle Network. Sustrans, Bristol. 